\title{
Political economy of fiscal unions 许
}

\author{
Jan Fidrmuc* \\ Department of Economics and Finance, Brunel University,Uxbridge, United Kingdom \\ CESIfo, Munich, Germany \\ Institute of Economic Studies, Charles University, Prague, Czech Republic
}

\section{A R T I C L E I N F O}

\section{Article history:}

Received 22 February 2015

Received in revised form 13 September 2015

Accepted 14 September 2015

Available online 25 September 2015

\section{JEL classification:}

D70

F59

H77

Keywords:

Fiscal federalism

Risk sharing

Disintegration

Median voter

\begin{abstract}
A B S T R A C T
Fiscal unions often use fiscal transfers to counter asymmetric shocks, but such transfers may be politically controversial. I present a model of a two-region fiscal union with region-specific shocks where the threat of secession imposes a limit on fiscal redistribution between regions. I show that both correlation of shocks across regions and their persistence over time are important for political support for integration. The gains from inter-regional risk sharing are potentially large when shocks are negatively correlated and temporary. In contrast, unions with negatively correlated permanent shocks are likely to be fragile.

(C) 2015 The Author. Published by Elsevier B.V. This is an open access article under the CC BY license (http://creativecommons.org/licenses/by/4.0/).
\end{abstract}

\section{Introduction}

One of the most intriguing questions of economics concerns the conditions under which deeper integration is possible and the circumstances that make integration fail. And fail it does remarkably often: more than 100 new countries emerged in the course of the $20^{\text {th }}$ century alone. Clearly, political and cultural motives such as a sense of separate identity and nationalism are of paramount importance as factors behind secessionist tendencies. Nevertheless, economic considerations also play an important role. Among them, the fact that unions tend to use fiscal policy to redistribute income across regions is often controversial. Such fiscal unions can feature inter-regional transfers that have been agreed upon, negotiated, and formalized explicitly, or that occur because of centralized automatic stabilizers such as progressive income tax, unemployment benefits, and the like. Disagreements about inter-regional fiscal redistribution can become an important driver of disintegration; fiscal transfers, and their perceived unfairness, played an

\footnotetext{
I I benefited from helpful comments and suggestions from seminar participants at University of Kobe, Hitotsubashi University, Development Bank of Japan, University of Auckland, University of Hong Kong, as well as conference participants at the annual meeting of the European Public Choice Society in Izmir, the 5th Annual CEDI Conference on Development and Institutions at Brunel University, the 19th Silvaplana Workshop on Political Economy, the CESifo Public Economics Conference 2011, and the Scottish Economic Society Conference 2013. I completed the first draft of this paper while I was visiting Hitotsubashi University in Tokyo whose hospitality, and financial support from the Fukino Project, I gratefully acknowledge. I benefited also from numerous comments and suggestions received from two anonymous referees, and Toke Aidt as the editor in charge of my paper.

* Department of Economics and Finance, Brunel University, Uxbridge, UB8, 3PH, United Kingdom. Tel.: + $441895266-528$.

E-mail addresses: Jan.Fidrmuc@brunel.ac.uk, jan@fidrmuc.net.
}

URL: http://www.fidrmuc.net/. 
important role in the break-up of Czechoslovakia and have significantly contributed to inter-regional tensions in Belgium, Spain, and the United Kingdom.

Nevertheless, fiscal transfers also have an important benefit in that they facilitate risk sharing. This aspect of integration has been highlighted by, among others, Beetsma and Jensen (2005), Gal and Monacelli (2008), and Farhi and Werning (2013). These studies emphasize the benefits - higher welfare due to consumption smoothing - that accrue to the participating countries when they enter into a mutual-insurance arrangement. As Farhi and Werning (2013) point out, these benefits are particularly large when fiscal policy is the only tool at the government's disposal (for example, when a country gives up independent monetary policy in order to participate in a currency union and thus loses the ability to use monetary policy to counter asymmetric shocks) and when financial markets are incomplete (because regions and individuals cannot use financial products to insure against shocks). Furthermore, the bigger and the more persistent are the shocks, the more attractive it is to form a fiscal union (Farhi and Werning, 2013).

The aforementioned contributions, while insightful, focus on the economic and welfare implications of fiscal unions. In this paper, instead, I consider the political economy of such arrangements. In a nutshell, a mutual-insurance arrangement that is optimal ex ante may be rejected by one of the parties ex post, once the shocks are realized. I formulate a model that is a dynamic version of the static model of Bolton and Roland (1997). It features a union composed of two countries with a centrally provided public good. As long as integration continues, fiscal policy reflects the union median voter's preferences which, in turn, depend on the aggregate effect of regional shocks. ${ }^{1}$ The two regions thus constitute an implicit fiscal union: fiscal redistribution occurs through centralized fiscal policy rather than by means of explicit inter-regional transfers. The regions, however, have the option to secede and implement their own preferred fiscal policy if the utility gain from doing so outweighs the cost of secession. Because of the shocks, a union that was previously stable can break-up following a particular regional shock, whether positive or negative. The opposite is also true; a region that preferred independence initially can come to prefer integration in the wake of a particular shock.

The analysis suggests that two aspects of shocks are important: the symmetry (or correlation) of shocks across regions and their persistence over time. With respect to the former, holding everything else constant, positively correlated (symmetric) shocks are good for the stability of integration. This is because the shocks change both regions' preferred fiscal policies in a similar manner: either both prefer more extensive redistribution or both prefer to scale it down. In this, my results echo the main finding of the optimum currency area theory (Mundell, 1961; McKinnon, 1963), which considers currency unions with common monetary rather than fiscal policy. The situation becomes more complicated when shocks are negatively correlated. In this case, fiscal-policy preferences diverge but the regions benefit from mutual insurance: under centralized fiscal policy, the region with a positive shock makes a net transfer to the region hit by a negative shock. This is where persistence of shocks proves crucial. With temporary shocks, the disutility from having suboptimal fiscal policy is short-lived and may be compensated by the benefits from risk sharing. When shocks are permanent, however, fiscal transfers become largely deterministic and unidirectional. The cost of having to put up with suboptimal fiscal policy, likewise, becomes long lasting. As a result, either region, or both, can prefer to secede in such a case so as to implement the region's preferred fiscal redistribution.

To illustrate the workings of the model, consider the disintegration of Czechoslovakia in 1993. ${ }^{2}$ The model predicts that a previously stable union can unravel due to asymmetric and persistent shocks. In Czechoslovakia's case, the shock was precipitated by the economic reforms initiated in 1990-91. While the reform took place in both parts of Czechoslovakia, it affected Slovakia much more severely than the Czech Republic: per-capita GDP fell by 12 percent in the Czech Republic during 1991-92 and by 20 percent in Slovakia; Czech unemployment, similarly, remained low, 2.6 percent in 1992, while the Slovak figure was 11.8 percent (see Fidrmuc et al., 1999, and Fidrmuc, 2000). This asymmetric effect of the reform shock was largely due to the greater dependence of Slovakia on trade with the former Eastern Block: much of the Slovak industry was built during the communist period so that the economy was highly dependent on trade with other communist countries (see Fidrmuc et al., 1999, and the references therein). This trade essentially collapsed after the communist regime and central planning were abandoned. The reform thus constituted a negative and persistent shock, which affected Slovakia more severely and more persistently than the Czech Republic. ${ }^{3}$ The greater cost of reform translated into greater support for redistribution in Slovakia than in the Czech Republic, which was reflected in the outcomes of the 1992 election (Fidrmuc, 2000).

The nature of the reform-induced shocks should have given an incentive to the Czech Republic to push for a break-up: it experienced a less-severe shock and it was also richer and therefore cross-subsidized Slovakia fiscally. ${ }^{4}$ However, the Czech Republic was twice the size of Slovakia ( 10 million vs 5 million) so that it had much more sway over fiscal policy than Slovakia. It was, therefore, the poorer country that pushed for the break-up. As I argue below, the poor region may prefer secession if income inequality in the union is high enough and/or the negative shock is sufficiently severe: then, the poor region can choose to secede in order to impose higher taxes and redistribute more, even if this comes at a cost of losing the fiscal transfer from the rich region.

\footnotetext{
1 The shocks need not be only output shocks (i.e. deviations from the trend growth rate): the analysis is general enough to allow also demographic shocks such as migration flows, or natural disasters.

${ }^{2}$ For an extensive discussion of the economic background of the break-up of Czechoslovakia, see Fidrmuc et al. (1999).

3 Slovak unemployment continued to rise steadily also after the break-up until it peaked at 19.2 percent in 1999 . Czech unemployment remained in single digits, peaking at 8.8 percent in 2000 .

${ }^{4}$ See Fidrmuc et al. (1999, Section 3.2) for some evidence of fiscal transfers within Czechoslovakia.
} 
Therefore, the break-up of Czechoslovakia can be attributed, at least in part, to the asymmetric repercussions of the economic reforms, and to the size and persistence of the adverse shock experienced by Slovakia. Had the shocks been more symmetric, or had the asymmetric repercussions in Slovakia been of less persistent nature, Czechoslovakia might have well survived. ${ }^{5}$

There is already a rich body of literature analyzing the incentives that countries face to secede: Alesina and Spolaore (1997, 2003a/ b), Alesina et al. (2000), Alesina and Perotti (1998), Bolton and Roland (1997), Goyal and Staal (2004), Le Breton and Weber (2003), Hindriks and Lockwood (2009), and Lülfesmann et al. (2015). However, much of this literature (with the exception of Alesina and Perotti, 1998, whose paper I discuss below) is static in nature: they consider the trade-off between heterogeneity of preferences and efficiency gains from integration (or efficiency loss from disintegration), without giving much thought to the factors that might drive preferences further apart or closer together as time passes. My analysis, in contrast, is concerned with offering insights on the reasons why unions that were originally stable subsequently break up.

Alesina and Perotti (1998) also consider fiscal integration between regions that are subject to idiosyncratic shocks. Their analytical framework, however, differs from mine in several important aspects. First, they consider shocks that are permanent and perfectly negatively correlated across regions. As such, their analysis does not allow inferences on the importance of either correlation or persistence of shocks. Second, they model shocks in a way that ensures that they do not affect income distribution and, correspondingly, they do not change the preferences over fiscal policy in the participating regions. Therefore, shocks in their model make the tax base stochastic but not the tax rate. Third, they assume that income distribution in each region is discontinuous: individuals belong to three discrete income classes. This means that the median voter in the union is always the same, regardless of the shocks. This, together with their assumption on the nature of shocks, implies that the tax rate under fiscal centralization becomes stochastic: specifically, it depends only on the shock to the region of the median voter. The tax base, in contrast, is constant under fiscal centralization because the region-specific shocks cancel each other out. Hence, their main conclusion is essentially the same as that of the static political economy literature discussed above: while fiscal integration offers some benefits in terms of risk sharing (the tax base that it constant over time), this comes at the cost of increased heterogeneity in policy preferences (tax rate that changes depending on the shocks' realization).

The paper is structured as follows: The next section introduces the model. Section 3 outlines the regions' incentives for secession and shows how stability of integration is determined by the nature of shocks. Section 4 concludes.

\section{The model}

I consider a union composed of two regions denoted by $k=a, b$. For simplicity, the regions are assumed to be of equal size (I discuss later the implications of assuming asymmetrically sized or multiple regions). The aggregate output of region $k$ at time $t$ consists of a deterministic and a stochastic term:

$$
Y_{k, t}=\bar{Y}_{k}+E_{k, t}
$$

where $\bar{Y}_{k}$ is the deterministic term and represents the region's potential output which I assume to be constant over time (adding a constant-trend growth rate would represent a trivial modification which I do not pursue for the sake of simplicity). $E_{k, t}$ is the stochastic component of region $k$ 's output in period $t$; this term can be either positive or negative. The stochastic component is intended to capture any factors that are idiosyncratic to the region and cause its output to fluctuate over time. As such, it can include business cycle fluctuations due to demand or supply shocks, weather- and climate-related shocks, natural disasters. discoveries of natural resources, and the like. I assume that the region-specific shocks are independent of each other but, as I discuss in more detail below, each shock can have spillover effect on the other region. Finally, the output of the union is given as the sum of the regional outputs.

The region's output can be expressed in per-capita terms:

$$
y_{k, t}=\bar{y}_{k}+\varepsilon_{k, t}
$$

where $\bar{y}_{k}$ is the average deterministic income and $\varepsilon_{k}$ is the per-capita income shock. I assume that the region-specific shock follows an $\mathrm{AR}(1)$ process

$$
\varepsilon_{k, t}=\rho_{k} \varepsilon_{k, t-1}+\eta_{k, t}
$$

where $\eta_{k, t}$ is white noise with a zero mean and variance $\sigma_{k}^{2}$. I assume that the persistence parameter, $\rho_{k}$, is between zero and one, $0 \leq \rho_{k} \leq 1$ : if shocks have persistent effect, they do not cause oscillation (assuming negative persistence parameter would be relatively

\footnotetext{
${ }^{5}$ Similar arguments could be put forward to explain the inter-regional tensions in Belgium and the UK. In Belgium, the economy of Wallonia, heavily dependent on mining and metallurgy, has been in decline from the 1950s onwards. Flanders, in the meantime, benefited from the expansion of services, and from the growth of trade through the port of Antwerp (Buyst, 2009). In the UK, the attraction of Scottish independence heavily reflects the expected revenue from North Sea oil. The recent referendum on Scottish independence was called when the oil price was rising (positive shock for Scotland) and the rest of the UK economy was in the grip of a major recession (negative shock). By the time the referendum took place, in September 2014, the oil price was falling again and the UK economy returned to positive growth, both of which made the prospect of Scotland seceding less attractive than continued integration.
} 
trivial as it would merely reverse the signs of the effects discussed below; it is, nevertheless, difficult to imagine shocks that would take such form). The union's average output is then

$$
y_{t}=\frac{\bar{y}_{a}+\bar{y}_{b}}{2}+\frac{\varepsilon_{a, t}+\varepsilon_{b, t}}{2}=\bar{y}+\varepsilon_{t}
$$

where, for notational purposes, parameters lacking a subscript are those pertaining to the union as a whole.

Each individual similarly has a deterministic income every period: for individual $i$ in region $k$, this is denoted as $\bar{v}_{i k}$. Individual incomes are assumed to take values between $v$ and $V$, where $v$ is a positive number that is high enough to ensure that no low-income individual experiences a negative income after an adverse shock. ${ }^{6}$ I make certain specific assumptions about the distribution of individual incomes:

1. Income distribution is skewed so that the median income, $\bar{v}_{m k}$, is always smaller than or equal to the average income, $\bar{v}_{m k} \leq \bar{y}_{k}$ and $\bar{v}_{m} \leq \bar{y}$, where subscripts $m k$ and $m$ denote the median individuals in region $k$ and in the union, respectively.

2. The distribution function, while skewed, is continuous. ${ }^{7}$

3. All individuals living in region $k$ encounter the same shock, $\varepsilon_{k, t}$ so that individual $i$ 's actual income is $v_{i k, t}=\bar{v}_{i k}+\varepsilon_{k, t}$. While this assumption may be too restrictive, the results of my model would hold also when assuming that the individual shocks encountered by all individuals living in the same region are positively correlated or even less restrictively, that only the average and median incomes are subject to similar shocks.

4. The union median income, $v_{m, t}$, is subject to the average shock, $\varepsilon_{t}$.

The fourth assumption may come across as counter-intuitive: the median individual must be either from region $a$ or $b$ and therefore is exposed to the shock affecting that region only. However, after the shocks are realized, the income distributions in the two regions shift relative to each other. Therefore, while the regional median voters are always the same individuals, the union's median individual is different every period (unless the two regional shocks exactly cancel out). The identity of the union median voter changes after every realization of the two regional shocks in such a way that the income of the new median voter differs from the income of the previous period's median voter by an amount that equals to the average shock. Therefore, assumption (4) follows from the assumption that the regional income distributions are continuous, and it constitutes a crucial difference between my model and that of Alesina and Perotti (1998), who assume that the union median voter always belongs to the same country (and her identity does not depend on the shocks). ${ }^{8}$ In contrast, in my model, the union's fiscal policy depends on the average economic conditions in the union: it is the level of median income and not the nationality of the medianincome individual that matters for fiscal redistribution. ${ }^{9}$

The following numerical example helps illustrate the rationale behind assumption (4): Region $a$ has 150 citizens with income distribution such that the poorest individual has an income of 100 , the next individual has 100.5 , then 101 , and so on in increments of 0.5 until the $49^{\text {th }}$ individual whose income is 124 . The $50^{\text {th }}$ individual's income is 125 , followed by 126 , and so on in increments of 1 until the $150^{\text {th }}$ individual whose income is 225 . The income distribution in region $b$ is identical with one exception: it has 149 citizens and the highest income is 224 (this ensures that the population of the union of these two regions is an odd number and the union median income can be clearly ascribed to a specific individual or individuals). The average income, at 154.2, exceeds the median income of 150 . Each region has exactly one individual with an income of 150 and therefore the pivotal voter can originate from either $a$ or $b$. Now consider the case where region $b$ individuals are hit by a per-capita shock of 20 while incomes in region $a$ remain unaffected. Correspondingly, the median income in $a$ remains the same as before while the median income in $b$ falls by 20 . The union median income falls by $10-140$ (with the average income in the union now being 144.2). Note that not only the median income but also the identity of the median voter changes. Before the shock, there were two individuals with an income of 150 , one in each region. The one in a still has the same income, whereas her counterpart in $b$ now has an income of 130 , and neither of them is the union's median individual after the shock. As before, the new median voter can be either from $a$ or $b$ as both will have exactly one individual with an income of 140 . Whether the new median voter is from $a$ (and therefore experiences no shock) or from $b$ (and has seen her income falling by 20) does not matter. What matters (as is explained in the discussion of how the tax rate is determined in the following two paragraphs) is the level of median income in the union and how it compares to the mean income.

Individuals derive utility from consumption of private and public goods with an increasing and concave utility function: $u^{\prime}()>$. and $u^{\prime \prime}()<$.0 . I assume that there is no lending or borrowing either by individuals or by the government. This assumption means that neither individuals nor the government can smooth the profile of consumption over time by accumulating or running down savings so that any consumption smoothing that occurs is the result of inter-regional risk sharing. The government has two instruments of fiscal policy at its disposal: a linear tax and a public good. Taxation is distortionary: levying a tax of $t$ is associated with a cost of $\frac{t_{t}^{2}}{2}$. Since there

\footnotetext{
${ }^{6}$ Taking $v=0$ would not affect the model's predictions, as long as the median-income individual never experiences a negative after-shock income. Negative median income would imply a tax rate exceeding 100 percent (see Eq. (7) below).

7 Hence, I specifically rule out discontinuos distributions such as the one assumed by Alesina and Perotti (1995).

8 See Eq. (6) in their paper, noting that the regional shocks are assumed to be perfectly negatively correlated so that they cancel out in the denominator.

9 Although the rationale behind the fourth assumption is fairly straightforward, as the following paragraph shows, the fact that the median voter responds to the average shock could also reflect bargaining between the two regions in the spirit of Besley and Coate (2003) and Aidt and Dutta (forthcoming).
} 
is no saving or borrowing by the government, the budget is balanced every period. The public good is thus financed by the total amount of tax revenue collected less the cost of taxation:

$$
g_{t}=\left(t_{t}-\frac{t_{t}^{2}}{2}\right) y_{t}
$$

Each individual receives the same amount of the public good. Private and public goods are assumed to be perfectly substitutable so that the utility function is linear in consumption. The consumption of individual $i$ from region $k$ then is:

$$
c_{i k, t}=\left(1-t_{t}\right) v_{i k, t}+\left(t_{t}-\frac{t_{t}^{2}}{2}\right) y_{t}
$$

The tax rate is determined by a union-wide vote. I assume voting takes place each period after the regional shocks have become known. Since voters' preferences are single-peaked and the individuals cannot save to smooth consumption intertemporarily, the tax rate will be chosen so as to maximize the median voter's consumption in period $t$ :

$$
t_{t}^{*}\left(y_{t}, v_{m, t}\right)=\frac{y_{t}-v_{m, t}}{y_{t}}
$$

The tax rate thus depends on the skewness of income distribution: the greater the difference between the average and median incomes, the higher the tax rate.

The regions' preferences over fiscal policy may differ from the preferences of the union median voter. In particular, each region's optimal tax rate is the rate that maximizes consumption of that region's median-income voter:

$$
t_{k, t}^{*}\left(y_{k, t}, v_{m k, t}\right)=\frac{y_{k, t}-v_{m k, t}}{y_{k, t}}
$$

Fiscal policy as chosen by the union median voter responds to region-specific shocks. In particular, the tax rate is countercyclical:

$$
\frac{\partial t_{t}^{*}}{\partial \varepsilon_{k, t}}=-\frac{1}{2} \frac{y_{t}-v_{m, t}}{y_{t}^{2}}<0
$$

so that the tax rate rises during a recession and falls during a boom. This is because the shock alters the skewness of income distribution, as captured by the ratio $\frac{v_{m, t}}{y_{t}}$. On the other hand, the public good is pro-cyclical:

$$
\frac{\partial g_{t}}{\partial \varepsilon_{k, t}}=\frac{1}{4} t_{t}^{2}>0
$$

Importantly, the union tax rate and public good provision change, as argued above, not because the preferences of the union's median voter change but because a different individual with a different income becomes pivotal in the union after the regional shocks have been realized.

The fact that fiscal policy responds to regional shocks stems from the preceding assumptions that the shocks are additive and the same shocks affect both the median and the average incomes. This implies that the poor are more vulnerable to shocks than the rich: since the shock is the same for everyone, it constitutes a greater share of the deterministic income of poor individuals. This can be rationalized by the fact that the ability to diversify risks tends to increase with income: the poor typically derive most or all of their earnings from labor while investment income can be an important component of earnings for the rich. The alternative assumption of multiplicative shocks, in contrast, would result in the shocks having no effect on fiscal policy: additive shocks alter the skewness of income distribution, $\frac{v_{m, t}}{y_{t}}=\frac{\bar{v}_{m, t}+\varepsilon_{t}}{\bar{y}+\varepsilon_{t}}$, whereas multiplicative shocks cancel out, $\frac{v_{m, t}}{y_{t}}=\frac{\bar{v}_{m, t}\left(1+\varepsilon_{t}\right)}{\bar{y}\left(1+\varepsilon_{t}\right)}$. $^{10}$

The region's preferred tax rate thus depends on that region's income distribution and the realization of the region-specific shock. Unless the income distributions and shocks are identical in both regions, their preferred tax rates will be different from each other and both will, in turn, differ from the union tax rate. Therefore, without efficiency gains, economies of scale, or other benefits of integration, the two regions would always prefer independence and fiscal autonomy to fiscal integration.

\footnotetext{
10 The latter is the reason why in Alesina and Perotti's (1998) model fiscal policy is independent of shocks in case of independence. With integration, in contrast, their assumption that the median voter stems always from the same region means that fiscal policy responds only to that region's shock.
} 


\section{Shocking aspects of fiscal integration}

\subsection{Integration vs secession}

The tax rate in Eq. (7) maximizes the consumption of the union's median voter during each period. The tax rates preferred by the two regional median voters are generally different from the union tax rate as well as from each other: they would be the same only if the two regions had the same income distributions and faced exactly the same shocks. Integration thus carries the cost of compromising over fiscal policy. On the other hand, integration brings about two important benefits. First, it implies efficiency gains and economies of scale because of free trade, unrestricted flow of factors of production, and access to a larger market. Second, and this is particularly important in the context of my analysis, integration is associated with risk sharing. Note that risk sharing and inter-regional redistribution are not explicitly determined in the present model: the regions do not vote on or bargain about interregional transfers. Instead, risk sharing occurs automatically because tax collection and fiscal transfers are determined at the unionwide level: they reflect the union-wide income distribution and the average of the two regional shocks. Moreover, risk sharing is only a side effect of fiscal policy: its main objective is redistribution from rich to poor. The rich region may be making a net transfer to the poor one even if the former is hit by a negative shock, as long as it remains richer than the poor region - but the size of the net transfer is sensitive to the shock.

Each period, the regions decide whether to remain in the union or secede. This decision takes place before the region-specific shocks are realized. Therefore, the decision is based on the expectations of current period's shocks, which in turn depend on the past shocks and their persistence. I assume that the persistence of past shocks is common knowledge. The decision on fiscal policy, on the other hand, is made after the shocks have been revealed and therefore taxes and transfers reflect the actual realization of shocks in the current period. The union breaks up whenever at least one region votes for secession.

Secession comes at a cost $\lambda_{k, t} \leq 0$, which I assume to be independent of the regional shocks. This cost reflects the loss of efficiency due to disintegration as well as the cost of creating a new regional government, military, etc. The cost is likely to be substantial immediately after breaking up the union and may fall thereafter. Specifying a particular time profile for this cost is not material for the model's results, however, given that the decision on secession reflects the shocks and the cost of secession is independent of those. Finally, the cost need not be symmetric: one of the regions can find secession less costly, for example, because of considerations such as national pride, patriotism, or historical legacies.

Given majority voting, the decision to secede therefore depends on whether the region's median voter is better off under integration or under secession, taking into account the difference between the region's preferred fiscal policy and the union's fiscal policy (this difference in turn depends on the realizations of region-specific shocks) and the efficiency loss due to secession. We can formalize this as follows (to simplify the notation, I use subscript $k$ when referring to the region's own variables while $-k$ denotes variables pertaining to the other region):

Definition 1. Region $k$ has an incentive to secede if the median voter expects greater consumption under secession than under integration, i.e. secession brings about a positive expected gain from secession

$$
\Delta_{k, t} \equiv E_{t}\left[c_{m k, t}\left(\varepsilon_{k, t}, \lambda_{k, t}\right)-c_{m k, t}^{u}\left(\varepsilon_{k, t}, \varepsilon_{-k, t}\right)\right]>0
$$

Here, $c_{m k, t}^{u}\left(\varepsilon_{k, t}, \varepsilon_{-k, t}\right)$ is the consumption of region $k$ 's median voter in case of continued integration. Given that the shocks are autocorrelated, (9) can be rewritten as follows:

$$
\Delta_{k, t} \equiv c_{m k, t}\left(\rho_{k} \varepsilon_{k, t-1}, \lambda_{k, t}\right)-c_{m k, t}^{u}\left(\rho_{k} \varepsilon_{k, t-1}, \rho_{-k} \varepsilon_{-k, t-1}\right)>0
$$

The outcome of the vote on secession therefore depends on the realization of previous period's shocks and their persistence.

As a digression, Eq. (9) is a necessary but not sufficient condition for secession. Whether secession occurs depends on the net present value of the gain from secession, $N P V S_{k, t} \equiv \sum_{s=0}^{\infty} \delta^{s} E_{t} \Delta_{k, t}+s$ (assuming secession is irreversible). The sufficient condition for secession then is $N P V S_{a, t}+N P V S_{b, t}>0$, reflecting the fact that as long as at least one region prefers integration, it can offer concession to the other region to prevent it from seceding. ${ }^{11}$ This, however, would introduce the possibility of strategic behavior, especially if $\lambda_{k, t}$ is not observable: either region could threaten to leave the union in order to elicit concessions from the other region. While interesting, such considerations are largely orthogonal to the question of the effect of shocks on integration. Therefore, I do not include them in this paper but they are discussed (briefly) in the final section.

To evaluate the expected gain from secession, note that under integration, the consumption of individual $i$ in region $k$ is:

$$
c_{i k, t}^{u}\left(\varepsilon_{k, t}, \varepsilon_{-k, t}\right)=v_{i k, t}+\frac{1}{2} \frac{y_{t}-v_{m, t}}{y_{t}}\left[\left(y_{t}-v_{i k, t}\right)+\left(v_{m, t}-v_{i k, t}\right)\right]
$$

\footnotetext{
${ }^{11}$ Bolton and Roland (1997) discuss bargaining over tax rate as union-preserving measure. Another possibility is inter-regional transfers (see Dixit and Londregan, 1998; Harstad, 2008; Claeys and Martire, 2014).
} 
Correspondingly, the consumption of region $k$ 's median voter under integration is

$$
c_{m k, t}^{u}\left(\varepsilon_{k, t}, \varepsilon_{-k, t}\right)=v_{m k, t}+\frac{1}{2} \frac{y_{t}-v_{m, t}}{y_{t}}\left[\left(y_{t}-v_{m k, t}\right)+\left(v_{m, t}-v_{m k, t}\right)\right]
$$

Finally, the consumption of region $k$ 's median voter under secession is the following (note that it incorporates the cost of secession, $\left.\lambda_{k, t}\right)$ :

$$
c_{m k, t}\left(\varepsilon_{k, t}, \lambda_{a, t}\right)=v_{m k, t}+\frac{1}{2} \frac{\left(y_{k, t}-v_{m k, t}\right)^{2}}{y_{k, t}}+\lambda_{k, t}
$$

After substituting from Eqs. (13) and (12), the expected gain from secession, $\Delta_{k, t}$ can be rewritten in the following manner: ${ }^{12}$

$$
\Delta_{k, t}=E_{t}\left[\frac{1}{2} \frac{\left(v_{m, t}-v_{m k, t}\right)^{2}}{y_{t}}+\frac{1}{2}\left(y_{k, t}-y_{t}\right)\left(1-\frac{v_{m k, t}^{2}}{y_{k} y_{t}}\right)\right]+\lambda_{k, t}
$$

The first term in Eq. (14) reflects the differences in income distributions between the union as a whole and region $k$. The greater the difference, the greater the incentive for the region to leave. Note that the incentive to secede increases with the absolute difference: even the poor region can gain from seceding because it can implement its preferred fiscal policy in that case. The second term captures the difference in tax base: the higher the region $k$ 's mean income compared to the union's mean income, the greater the incentive to secede. Finally, the last term captures the cost of secession, which is always negative by assumption.

For the relatively rich region, therefore, the first two terms are both positive. If secession were costless, the rich region would always want to secede. For the poor region, the first term is positive but the second term is negative so that this region may prefer continued integration even if secession were possible at no cost. It is, however, possible that the poor region would prefer to secede, for example, if its mean income is only slightly lower than the union mean income (so that the positive tax effect is modest) but its income distribution is much more skewed than in the other region. In such a case, the benefit from being able to implement the region's preferred fiscal policy might outweigh the cost of losing the net transfer from the richer region. The break-up of Czechoslovakia, instigated by Slovakia, the poorer country in the federation, may be an example of this (as discussed in the Introduction).

\subsection{Effects of shocks}

Next, I turn to the role played by the region-specific shocks. Voters in one or both regions may be induced to vote for secession either in response to the home region's shock or because of the other region's shock: either shock can raise or reduce the incentive for secession captured by the expected gain from secession, $\Delta_{k, t}$.

The following two assumptions help make the analysis tractable:

A1 Region $a$ is always richer than region $b$; this holds both for the median incomes as well as (weakly) for the average incomes: $v_{m a, t}>v_{m, t}>v_{m b, t}$ and $y_{a, t} \geq y_{t} \geq y_{b, t}$. This is not to say that shocks cannot be large enough to reverse the relative ordering of the two regions. Rather, it merely means that which ever region happens to be richer is labeled as region $a$. The implication is that region $a$ 's median voter would prefer strictly lower extent of redistribution than the union median voter if she were pivotal, whereas the opposite is true for region $b$ 's median voter: $\frac{v_{m a, t}}{y}>\frac{v_{m, t}}{y}>\frac{v_{m b, t}}{y}$.

A2 The median income in either region does not exceed the union's average income: $v_{m k, t}<y_{t}$ (i.e. neither median voter would prefer $t_{t}^{*}=0$ if pivotal in the union). This assumption may be reasonable for many but not all fiscal unions: the median income in Luxembourg is probably greater than the average income in the EU or the Eurozone. I discuss below the implication of relaxing it.

Because the vote on secession takes place before the shocks are realized, the decision is based on the expectations of the current period's shocks which in turn depend on the realizations of previous period's shocks and their persistence, $E_{t} \varepsilon_{k, t}=\rho_{k} \varepsilon_{k, t}-1$ and $E_{t} \varepsilon_{-k, t}=\rho_{-k} \varepsilon_{-k, t-1}$. I consider the impact of the other region's shock first:

Proposition 1. (a) Assuming that the persistence parameter is positive, $\rho_{-k}>0$, positive shock in the other region at time $t-1$ reduces the home region's incentive to secede at time t, a negative shock increases the incentive to secede.

$$
\frac{\partial \Delta_{k, t}}{\partial \varepsilon_{-k, t-1}}<0
$$

(b) The effect is greater (in absolute value) for region a than for region $b$ (ceteris paribus).

$\overline{12}$ Note that the variables pertaining to the union, $v_{m, t}$ and $y_{t}$, depend on both shocks, $\left(\varepsilon_{k, t}, \varepsilon_{-k, t}\right)$, whereas $v_{m k, t}$ and $y_{k, t}$ only depend on $\varepsilon_{k, t}$. 
Proof. (a) Differentiating $\Delta_{k, t}$ with respect to $\varepsilon_{-k, t-1}$ while holding $\varepsilon_{k, t-1}$ constant yields:

$$
\frac{\partial \Delta_{k, t}}{\boldsymbol{\partial} \varepsilon_{-k, t-1}}=\left[\frac{1}{2} \frac{v_{m, t}-v_{m k, t}}{y_{t}}-\frac{1}{4} \frac{\left(v_{m, t}-v_{m k, t}\right)^{2}}{y_{t}^{2}}-\frac{1}{4} \frac{y_{t}^{2}-v_{m k, t}^{2}}{y_{t}^{2}}\right] \rho_{-k}
$$

The RHS of Eq. (15) can be reduced to $\frac{1}{4} \frac{1}{y_{t}^{2}}\left(y_{t}-v_{m, t}+2 v_{m k, t}\right)\left(v_{m, t}-y_{t}\right) \rho_{-k}$. The second term in parentheses is negative for both regions by assumption A2. Given that I assume that the intertemporal correlation term is positive, the expression is negative for both regions. (b) Assumption A1 implies $v_{m a, t}>v_{m b, t}$, so that the absolute value of this expression is higher for region $a$ than for region $b$.

The upshot of Proposition 1 is that for a given realization of the region's own shock, $\varepsilon_{k, t}-1$, either region is more likely to secede if the other region encountered a negative shock in the preceding period, $\varepsilon_{-k, t-1}<0$. The intuition underlying this result is simple. For a given own shock, $\varepsilon_{k, t}-1$, a positive shock in the other region reduces the expected union tax rate (tax rate effect) and raises the expected level of government spending (transfer effect). The transfer effect increases consumption in both regions. The tax effect is different, though. The median voter in region $a$ prefers a lower tax rate than the union tax rate by assumption A1. A positive shock in region $b$ decreases the expected union tax rate, so that the expected disparity between region $a$ 's preferred tax rate and the union tax rate shrinks. The transfer effect also implies that the incentive for region $a$ to secede falls after a positive shock in region $b$. On the other hand, region $b$ 's preferred tax rate is higher than the tax rate chosen by the union median voter. Thus, as the expected union tax rate falls, the expected disparity between the two tax rates widens even further. Hence, the tax effect and the transfer effect go in opposite directions for region $b$. The response of region $b$ will therefore be smaller than the response of region $a$, even though the overall effect is unambiguously positive for both regions.

Without the assumption A2, the sign of Eq. (15) may be positive so that the home region would be more likely to secede after a positive shock in the other region. It also implies that the median voter of the richer region would prefer a zero tax rate if pivotal in the union. Both of these effects are rather counter-intuitive and difficult to rationalize, and therefore, I disregard this possibility.

Analyzing how the decision on secession is affected by the region's own shock is less straightforward. Differentiating $\Delta_{k, t}$ with respect to $\varepsilon_{k, t-1}$ while holding $\varepsilon_{-k, t-1}$ constant yields:

$$
\frac{\partial \Delta_{k, t}}{\partial \varepsilon_{k, t-1}}=\left[-\frac{1}{2} \frac{v_{m, t}-v_{m k, t}}{y_{t}}-\frac{1}{4} \frac{\left(v_{m, t}-v_{m k, t}\right)^{2}}{y_{t}^{2}}+\frac{v_{m k, t}}{y_{k, t}}-\frac{v_{m k, t}}{y_{t}}-\frac{1}{2} \frac{v_{m k, t}^{2}}{y_{k, t}^{2}}+\frac{1}{4}+\frac{1}{4} \frac{v_{m k, t}^{2}}{y_{t}^{2}}\right] \rho_{k}
$$

The sign of this expression is analytically ambiguous. Therefore, I consider first a simplified case:

Proposition 2. If mean incomes before shocks are the same in both regions, i.e. $y_{a, t}=y_{b, t}=y_{t}$, and assuming that the persistence parameter is positive, $\rho_{k}>0$, then:

(a) A positive shock in region a will increase this region's incentive to secede. A negative shock in region a will reduce this region's incentive to split off:

$$
\frac{\partial \Delta_{a, t}}{\partial \varepsilon_{a, t-1}}>0
$$

(b) The response of region $b$ depends on the difference between the median income in $b$ and the union's median: $\frac{\partial \Delta_{b, t}}{\partial \varepsilon_{b, t-1}}$ is positive for small $\left(v_{m b, t}-v_{m, t}\right)$ and negative otherwise.

Proof. For $y_{a, t}=y_{b, t}=y_{t}$, Eq. (16) can be rewritten as follows:

$$
\begin{aligned}
\frac{\partial \Delta_{k, t}}{\partial \varepsilon_{k, t-1}} & =\left[-\frac{1}{2} \frac{v_{m, t}-v_{m k, t}}{y_{t}}-\frac{1}{4} \frac{\left(v_{m, t}-v_{m k, t}\right)^{2}}{y_{t}^{2}}+\frac{1}{4} \frac{y_{t}^{2}-v_{m k, t}^{2}}{y_{t}^{2}}\right] \rho_{k} \\
& =\left[\frac{1}{4}\left(y_{t}^{2}-v_{m, t}^{2}\right)+\frac{1}{2}\left(v_{m k, t}-v_{m, t}\right)\left(y_{t}-v_{m k, t}\right)\right] \frac{1}{y_{t}^{2}} \rho_{k}
\end{aligned}
$$

The first term of the expression in the second line above is always positive. The second term is positive for region $a$ and negative for region $b$; this follows from assumptions $\mathrm{A} 1$ and $\mathrm{A} 2$. Hence, $\frac{\partial \Delta_{a, t}}{\partial \varepsilon_{a, t-1}}$ is positive, whereas $\frac{\partial \Delta_{b, t}}{\partial \varepsilon_{b, t-1}}$ can be either positive or negative. When $\left(v_{m b, t}-v_{m, t}\right)$ is small in absolute value, the first term outweighs the second term, and the opposite is true for large $\left(v_{m b, t}-v_{m, t}\right)$

The result described in Proposition 2 again reflects the tax effect and the transfer effect. A positive shock in either region reduces the expected union tax rate and raises the expected transfer. In case of region $A$, the median voter's preferred tax rate is lower than the 
union's tax rate. After the shock, the expectations of both the union's tax rate and the region's tax rate fall. However, the region's own preferred tax rate falls by more, thus further increasing the difference between the two tax rates. ${ }^{13}$ The transfer, on the other hand, rises in the wake of a positive shock. However, region $a$ 's tax base $y_{a, t}$ rises by more that the union's tax base $y_{t}$. This implies that region $a$ would enjoy a greater increase in the level of the transfer in case of secession. Both these effects make secession more attractive for region $a .^{14}$

In region $b$, the median voter's preferred tax rate is above the union's tax rate. A positive shock results in the reduction of both the expected union's tax rate as well as the region $b$ 's expected tax rate. The expectation of the region's preferred tax rate falls by more and the difference in this case thus shrinks. The transfer effect on region $b$ is similar the effect on region $a$ described above. Hence, for region $b$, the tax and transfer effects go in opposite directions. Depending on how different the two regional income distributions are from each other, the overall effect therefore can be positive or negative.

\subsection{Persistence and correlation of shocks}

The discussion so far has been a rather straightforward extension of Bolton and Roland's analysis, discussing how changes in the regional distribution of incomes (caused by region-specific shocks) alter the incentives for secession and thus induce the union to break up. Next, I consider how the stability of integration - and in turn the likelihood of disintegration - depends on the nature of shocks. So far, I considered only the response of each region to their own shock and to the shock affecting their union partner. Now I look at the specific properties of the shocks: their persistence over time and their correlation across regions.

Proposition 3. Persistence: Assume the union is a-priori stable, i.e. neither region would vote for secession in the absence of shocks:

$$
\left.\Delta_{k, t}\left(\rho_{k} \varepsilon_{k, t-1}, \rho_{-k} \varepsilon_{-k, t-1}\right)\right|_{\varepsilon_{k, t-1}=\varepsilon_{-k, t-1}=0} \leq 0
$$

Then, assuming the other region's shock is white noise, $\rho_{-k, t-1}=0$, for a positive value of own shock, $\varepsilon_{k, t}-1>0$, there is a value of the persistence parameter $\bar{\rho}_{k}$ such that $\Delta_{k, t}\left(\rho_{k} \varepsilon_{k, t}-1,0\right) \leq 0$ for every $\rho_{k} \leq \bar{\rho}_{k}$. Similarly, assuming the home region's shock is white noise, $\rho_{k, t-1}=0$, for a negative shock in the other region, $\varepsilon_{-k, t-1}<0$, there is a value of the persistence parameter $\bar{\rho}_{-k}$ such that $\Delta_{k, t}\left(0, \rho_{-k} \varepsilon_{-k, t-1}\right) \leq 0$ for every $\rho_{-k} \leq \bar{\rho}_{-k}$. If $\bar{\rho}_{k}$ and $\bar{\rho}_{-k}$ are less then one, then secession takes place if $\rho_{k}>\bar{\rho}_{k}$ and $\rho_{-k}>\bar{\rho}_{-k}$, respectively.

Proof. The expected gain from secession rises for $\varepsilon_{k, t-1}>0$ and/or $\varepsilon_{-k, t-1}<0$ (and falls for $\varepsilon_{k, t-1}<0$ and/or $\varepsilon_{-k, t-1}>0$ ). As follows from Eqs. (15) and (16), $\frac{\partial \Delta_{k, t}}{\partial \varepsilon_{k, t-1}}$ and $\frac{\partial \Delta_{k, t}}{\partial \varepsilon_{-k, t-1}}$ equal zero for $\rho_{k}=0$ and $\rho_{-k}=0$, respectively. Hence, if both shocks are white noise, they do not affect the expected gain from secession and hence they do not undermine the stability of integration. If either shock is persistent, $\rho_{k}>0$ or $\rho_{-k}>0$, then the following holds

$$
\begin{aligned}
& \Delta_{k, t}\left(\rho_{k} \varepsilon_{k, t-1}, 0\right) \mid \rho_{k, t-1}>0, \varepsilon_{k, t-1}>0 \\
& \Delta_{k, t}\left(0, \rho_{-k} \varepsilon_{-k, t-1}\right) \mid \rho_{-k, t-1}<0, \varepsilon_{-k, t-1}<0 \\
& \rho_{k, t-1}>\left.\Delta_{k, t}\right|_{\rho_{k, t-1}=\rho_{-k, t-1}=0}=0
\end{aligned}
$$

By continuity, $\Delta_{k, t}\left(\rho_{k} \varepsilon_{k, t-1}, 0\right) \leq 0\left(\Delta_{k, t}\left(0, \rho_{-k} \varepsilon_{-k, t-1}\right) \leq 0\right)$ holds for at least part of the interval $0<\rho_{k} \leq 1\left(0<\rho_{-k} \leq 1\right)$.

The upshot of Proposition 3 is that if shocks are sufficiently short-lived, they will not give a sufficient incentive for either region to secede: the gain from seceding would be so small so as to be outweighed by the efficiency loss due to disintegration. On the other hand, when shocks are sufficiently persistent, they can bring the union down.

So far, I have been assuming that the regional shocks are fully independent of one another, i.e. each shock only affects incomes in one region. In open economies, this is unlikely to be the case: shocks have spillover effects because of trade, migration and investment flows, due to remittances from migrants or because of dividend payments on past investments. Therefore, I now consider the case when shocks have spillover effects.

Proposition 4. Correlation: Positive correlation (spillover) of shocks reduces the probability of secession, whereas negative correlation increases that probability, taking the persistence of shocks as given.

\footnotetext{
13 Recall that the region's preferred tax rate fully responds to the home-region shock $\varepsilon_{k, t}$, whereas the union's tax rate responds to the average shock, $\varepsilon_{t} \equiv \frac{\varepsilon_{a, t}+\varepsilon_{b, t}}{2}$. Unless $\varepsilon_{a, t}=\varepsilon_{b, t}$, the region's tax rate fall by more than the union's tax rate in response to a positive home shock.

${ }^{14}$ If the average incomes in the two regions are different, $y_{a, t} \neq y_{b, t}$, the effect of the region's own shock on its incentive to secede is ambiguous for both regions. Numerical simulations with $y_{a, t}>y_{b, t}$ ( using $y=10, v_{m}=7.5$, and shocks between -3 and 3 ) yield result identical to Proposition 2 , i.e. $\frac{\partial \Delta_{a, t}}{\partial \varepsilon_{a, t-1}}$ is always positive whereas $\frac{\partial \Delta_{b, t}}{\partial \varepsilon_{b, t-1}}$ is positive for small $\left(v_{m, t}-v_{m b, t}\right)$ and negative otherwise.
} 
Proof. Assume shocks' effects are correlated in that there is a spillover between the regions so that individual incomes in region $k$ also depend on the shock experienced by the other region, $\frac{\partial v_{i k t}}{\partial \varepsilon_{-k t}}=\gamma$. Then, for a given home-region's shock, the shock in the other region affects the median voter's expected gain from secession in the following manner:

$$
\begin{aligned}
\frac{\partial \Delta_{k, t}}{\partial \varepsilon_{-k, t-1}}= & {\left[\frac{1}{2} \frac{v_{m, t}-v_{m k, t}}{y_{t}}-\frac{1}{4} \frac{\left(v_{m, t}-v_{m k, t}\right)^{2}}{y_{t}^{2}}-\frac{1}{4} \frac{y_{t}^{2}-v_{m k, t}^{2}}{y_{t}^{2}}\right] \rho_{-k} } \\
& +\left[-\frac{1}{2} \frac{v_{m, t}-v_{m k, t}}{y_{t}}-\frac{1}{4} \frac{\left(v_{m, t}-v_{m k, t}\right)^{2}}{y_{t}^{2}}+\frac{v_{m k, t}}{y_{k, t}}-\frac{v_{m k, t}}{y_{t}}-\frac{1}{2} \frac{v_{m k, t}^{2}}{y_{k, t}^{2}}+\frac{1}{4}+\frac{1}{4} \frac{v_{m k, t}^{2}}{y_{t}^{2}}\right] \gamma \rho_{k}
\end{aligned}
$$

The first term corresponds to the expression for $\frac{\partial \Delta_{k, t}}{\partial \varepsilon_{-k, t-1}}$ when shocks are independent, as in Eq. (15), whereas the second term captures the spillover effect of the other region's shock (cf. Eq. (16)). As shown by Proposition 1, the term in the first brackets is negative, while according to Proposition 2 the term in the second brackets is positive (assuming $v_{m b, t}-v_{m, t}$ is sufficiently small). Hence, if the spillover effects of shocks are positive, $\gamma>0$, so that the shocks become ex post positively correlated, the second term mitigates the effect of the first term. On the other hand, if shocks are negatively correlated, both effects go in the same direction, thus increasing the probability of secession.

The last two propositions contrasts with the key insight of the OCA literature that is concerned with monetary integration. In that literature, only the correlation (symmetry) of shocks plays a role: currency unions are predicted to be viable if the shocks are positively correlated. The present paper adds another dimension: the persistence of shocks. In particular, fiscal unions can be stable even with negatively correlated shocks, as long as these shocks are sufficiently transient.

\subsection{Discussion}

A number of observations can be made about other factors underlying disintegration:

Risk sharing: Integration reduces the uncertainty about fiscal policy. Both the tax rate and the tax base are more volatile after secession than under integration. Integration thus helps smooth taxes and in turn reduces the volatility of disposable income and consumption. The potential benefits from risk sharing are at their greatest when shocks are negatively correlated and temporary.

Uncertainty: An increase in the variance of either shock, $\sigma_{k}^{2}$, increases the probability of disintegration, but only if the shocks are persistent. High variance increases the likelihood that a sufficiently large shock will occur to prompt one of the region to split off. This is likely to have happened in the case of Czechoslovakia (discussed earlier) and possibly also for other multi-ethnic unions in Central and Eastern Europe: the economic reforms implemented in the late 1980s and early 1990s were associated with a substantial increase in the volatility of asymmetric shocks as well as with changes in their inter-regional correlation and persistence.

Decentralization may destabilize integration arrangements if it decreases the spillovers of shocks between regions. For example, promoting the use of regional or minority languages - such as French in Quebec, Catalan in Catalonia, or Dutch in Flanders - restricts labor mobility across language boundaries (see Bartz and Fuchs-Schündeln, 2012). Similarly, regional policies promoting local firms can make the regions more vulnerable to asymmetric shocks if the regions are dominated by different industries. All these measures in turn reduce the spillovers of shocks across regions. Hence, the efforts to rescue troubled unions by increasing the autonomy of regions may prove futile, and federalization, or devolution, may prove to be a step toward the slippery slope of disintegration.

Size: Relaxing the assumption of regions being equally sized, and assuming (for simplicity) that the cost of secession is independent of size, the smaller region stands to gain more by seceding than the larger region. Given that the union's fiscal policy responds to the average shock, the larger region's shock affects the centralized fiscal policy more than the smaller region's shock. This implies that the smaller region is more likely to find itself preferring secession following a particular realization of either its own shock or the other region's shock. The relative size helps explain why disintegrations often involve the secession of a relatively small part of the original union, such as Slovakia breaking away from the Czech Republic, the Baltic countries from the Soviet Union or Slovenia and Croatia from the former Yugoslavia. Furthermore, allowing more than two regions in the model would be equivalent to asymmetric size. For instance, assume that there are three equally sized regions. From the point of view of each region, the decision on secession involves considering its own shock, and the aggregate shock in the rest of the union, with the rest of the union being twice the size of the home region.

\section{Conclusions}

In this paper, I seek to shed light on the reasons why unions that survived for decades or centuries suddenly unravel. While there are often many very diverse motives for secessionist movements, my focus is on fiscal policy and fiscal redistribution. On the one hand, inter-regional fiscal transfers provide insurance against asymmetric and region-specific shocks. In doing so, they help smooth consumption over time. However, fiscal redistribution typically requires that regions delegate control over tax setting and redistribution to a higher level of government and may end up with fiscal policy that deviates from their preferences. The net balance of costs and benefits of fiscal integration can, correspondingly, be positive or negative. 
I show that two aspects region-specific shocks are crucial for the stability of fiscal unions: the correlation (symmetry) of shocks and their persistence. When the participating regions experience symmetric shocks, they do not have much incentive to quit (regardless of whether the shocks are temporary or persistent). Things become more complicated when shocks are uncorrelated or negatively correlated. The benefits of risk sharing can be substantial in this case. However, a sufficiently large and persistent shock can turn risk sharing into a long-term unidirectional transfer. Europe abounds with examples of this: former Czechoslovakia (where historically fiscal transfers flowed from the Czech Republic to Slovakia), Belgium (Flanders cross-subsidizing Wallonia), Germany (the West making massive fiscal transfers to the East), or the UK (where a major attraction of the Scottish independence has been the prospect of keeping the bulk of North Sea oil revenue, which at present accrue to the UK's centralized budget). Such transfers constitute redistribution caused by past shocks, not insurance against future ones. The reluctance with which these transfers are made, and the conditions, limitations, and safeguards attached to them, underscore the importance of political economy aspects of integration.

Importantly, fiscal unions may be politically unpopular also in the countries on the receiving end of fiscal transfers. The protests in Greece and Spain against austerity measures imposed from Brussels and Frankfurt demonstrate this; the break-up of Czechoslovakia, instigated by Slovakia, the poorer partner in the federation, is another example. Quitting the fiscal union allows the richer country to lower taxes and scale down redistribution. The poorer country can do the opposite, increase taxes and redistribute more. In both cases, the post-independence fiscal policy better reflects the preferences of the median voter: secession brings the government closer to the people, in the rich and poor country alike. Depending on other factors, such as, for example, the relative sizes of the countries, it can be the richer or the poorer region that elects to secede.

A number of potentially important considerations have been left out of the analysis. First, in the presence of continued uncertainty about future shocks, maintaining the fiscal union is associated with an option value of waiting which is likely to be positive. In particular, the temptation to secede, stemming from the past shocks, can be undone by future economic fluctuations. Assuming that secession is irreversible, countries therefore face a strong incentive to be cautious. This aspect of decision making under uncertainty has been analyzed extensively by Dixit and Pindyck (1994) and others.

Second, the incentive to secede would be different if the regions participating in a fiscal union could borrow to mitigate the adverse effects of negative shocks. In this case, the regions could engage in intertemporal rather than inter-regional insurance. The role played by financial markets is analyzed by Farhi and Werning (2013) who argue that the ability of regions to self-insure against asymmetric shocks diminishes the gains from fiscal integration. When considering the political economy implications, anything that makes regions less dependent on inter-regional transfers also diminishes their incentive to secede in the wake of particularly large shocks. Therefore, fiscal unions which allow the participating regions to self-insure in the financial markets will entail lower gains from integration but should also prove more stable over time.

Finally, unless both countries wish to secede, there is a potential for bargaining and side payments whereby one country agrees to compensate the other sufficiently to stop it from seceding. As Claeys and Martire (2014) argue using examples from Spain and Italy, side payments are often incorporated into fiscal federalism regimes in the real world. Harstad (2008) shows, however, that bargaining and side payments create an incentive for both regions to behave strategically. In particular, the secession-prone region is likely to appoint a negotiator who values integration less than the median voter, so as to extract maximum transfer from the other side (the outcome of the 2015 Greek election may be an illustration of this). While interesting and certainly worthwhile exploring, this would add an additional layer to the analysis. My model sheds light on factors that shape the underlying incentive to secede, leaving the strategic aspects of bargaining about secession aside.

\section{References}

Aidt, T., Dutta, J., 2015. Fiscal federalism and electoral accountability. J. Public Econ. Theory (forthcoming).

Alesina, A., Perotti, R., 1998. Economic risk and political risk in fiscal unions. Econ. J. 108 (449), 989-1008.

Alesina, A., Spolaore, E., 1997. On the number and size of nations. Q. J. Econ. 112 (4), 1027-1056.

Alesina, A., Spolaore, E., 2003a. War, peace and size of countries. J. Public Econ. 89 (7), 1333-1354.

Alesina, A., Spolaore, E., 2003b. The Size of Nations. MIT Press, Cambridge, MA.

Alesina, A., Spolaore, E., Wacziarg, R., 2000. Economic integration and political disintegration. Am. Econ. Rev. 90 (5), $1276-1296$.

Bartz, K., Fuchs-Schündeln, N., 2012. The role of borders, languages, and currencies as obstacles to labor market integration. Eur. Econ. Rev. 56 (6), $1148-1163$.

Beetsma, R.M.W.J., Jensen, H., 2005. Monetary and fiscal policy interactions in a micro-founded model of a monetary union. J. Int. Econ. 67, $320-352$.

Besley, T., Coate, S., 2003. Centralized versus decentralized provision of local public goods: a political economy approach. J. Public Econ. 87 (12), $2611-2637$.

Bolton, P., Roland, G., 1997. The break up of nations: a political economy analysis. Q. J. Econ. 112 (4), 1057-1090.

Buyst, E., 2009. Reversal of Fortune in a Small, Open Economy: Regional GDP in Belgium, 1896-2000. Vives discussion paper 8. VIVES, KUL Leuven.

Claeys, P., Martire, F., 2014. "If you want me to stay, pay: A model of asymmetric federalism in centralised countries". mimeo.

Dixit, A.K., Londregan, J., 1998. Fiscal federalism and redistributive politics. J. Public Econ. 68 (2), 153-180.

Dixit, A.K., Pindyck, R.S., 1994. Investment Under Uncertainty. Princeton University Press, Princeton, NJ.

Farhi, E., Werning, I., 2013. “Fiscal Unions.” MIT, mimeo.

Fidrmuc, J., 2000. Political support for reforms: economics of voting in transition countries. Eur. Econ. Rev. 44 (8), $1491-1513$.

Fidrmuc, J., Horvath, J., Fidrmuc, J., 1999. Stability of monetary unions: lessons from the break up of Czechoslovakia. J. Comp. Econ. 27 (4), $753-781$.

Gal, J., Monacelli, T., 2008. Optimal monetary and fiscal policy in a currency union. J. Int. Econ. 76, 116-132.

Goyal, S., Staal, K., 2004. The political economy of regionalism. Eur. Econ. Rev. 48, 563-593.

Harstad, B., 2008. Do side payments help? Collective decisions and strategic delegation. J. Eur. Econ. Assoc. 6 (2-3), $468-477$.

Hindriks, J., Lockwood, B., 2009. Decentralization and electoral accountability: incentives, separation and voter welfare. Eur. J. Polit. Econ. 25 (3), $385-397$.

Le Breton, M., Weber, S., 2003. The art of making everybody happy: how to prevent a secession. IMF Staff. Pap. 50 (3), $403-435$.

Lülfesmann, C., Kessler, A.S., Myers, G.M., 2015. The architecture of federations: constitutions, bargaining, and moral hazard. J. Public Econ. 124, 18-29.

McKinnon, R.I., 1963. Optimum currency areas. Am. Econ. Rev. 53, 717-725.

Mundell, R.A., 1961. A theory of optimum currency areas. Am. Econ. Rev. 51, 657-665. 